Published by LPMP Imperium

Journal homepage: https:/ / ejournal.imperiuminstitute.org/ index.php/JMSAB

\title{
Analisis Corporate Governance dalam Kemitraan Pemerintah dan Badan Usaha Bidang Infrastruktur
}

\section{Tyahya Whisnu Hendratni*, Hindradjid Harsono, Soemarsono DW \\ Fakultas Ekonomi dan Bisnis, Universitas Pancasila}

\begin{abstract}
The purpose of the study was to determine: The influence of Corporate Governance in the Government and Business Entity Partnership (PPP) in the infrastructure sector, the main factors that can affect the Government and Business Entity Partnership (PPP) in the Infrastructure sector and How to apply the principles of Corporate Governance in the Government and Business Entity Partnership ( PPP ) in the infrastructure sector in Indonesia. The population and subjects studied are a group of people who understand the Government and Business Entity Partnership (PPP), namely from the Association of Professional Experts on Government Partnerships and Indonesian Business Entities (PAP-KPBUI) as many as 142 people. For data analysis used in this study use Ordinary Least Square (OLS) regression estimation technique to analyze the relationship between the independent variable and the dependent variable. Data processing is carried out using SPSS 23. The results of the study can be seen that the variables of Transparency, Accountability, Responsibility, Independence, and Justice together have a contribution of influence of PPP in the Infrastructure sector.
\end{abstract}

Keywords: Government investment in infrastructure, Government and Business Entity Partnership (PPP), Corporate Governance in partnership, Association of Government Partnership Professional Experts and Business Entities.

\section{Corresponding Author:}

Tyahya Whisnu Hendratni

Fakultas Ekonomi dan Bisnis, Universitas Pancasila

Email: tyahyawhisnu@univpancasila.ac.id

(C) The Author(s) 2021

DOI: https:/ / doi.org/ 10.36407/jmsab.v4i1.327

\section{(c) (2)}

CC BY: This license allows reusers to distribute, remix, adapt, and build upon the material in any medium or format, so long as attribution is given to the creator. The license allows for commercial use.
JMSAB
Research Paper

Management

Received: 12 Apr 2021

Accepted: 20 Jun 2021

Online: 30 Jun 2021

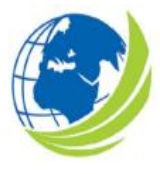

Jurnal Manajemen Strategi dan Aplikasi Bisnis, Vol 4, No. 1, 2021, pp. 199 - 206

eISSN 2655-237X 


\section{PENDAHULUAN}

Kurang optimalnya penerapan Good Corporate Governance disebabkan adanya hambatanhambatan. Hambatan utama dalam penerapan prinsip tata kelola perusahaan yaitu tidak adanya sanksi bagi perusahaan yang tidak melaksanakannya dan faktor budaya masyarakat yang lebih mematuhi hukum informal yang berupa kebiasaan daripada hukum formal. Rekomendasi untuk mengatasi hambatan tersebut adalah negara dan perangkatnya sebagai regulator harus memaksa perusahaan untuk menerapkan prinsip tata kelola perusahaan dan budaya perusahaan sebagai sebuah kesatuan nilai harmonis yang diiringi dengan melaksanakan peraturan perundangundangan dan penegakan hukum secara konsisten (consistent law enforcement), dunia usaha sebagai pelaku pasar menerapkan tata kelola perusahaan yang baik sebagai pedoman dasar pelaksanaan usaha, dan masyarakat melakukan kontrol sosial (social control) secara obyektif dan bertanggung jawab. (Mundzir, 2016).

Menurut Chandra (2007), setiap perusahaan memiliki visi dan misi dari keberadaannya. Visi dan misi tersebut merupakan pernyataan tertulis tentang tujuan-tujuan kegiatan usaha yang akan dilakukan. Tentunya kegiatan terencana dan terprogram ini dapat tercapai dengan keberadaan sistem tata kelola perusahaan yang baik. Di samping itu perlu terbentuk kerja sama tim yang baik dengan berbagai pihak, terutama dari seluruh karyawan dan manajemen puncak. Sistem tata kelola organisasi perusahaan yang baik ini menuntut dibangunnya dan dijalankannya prinsip-prinsip tata kelola perusahaan (GCG) dalam proses manajerial perusahaan. Dengan mengenal prinsip-prinsip yang berlaku secara universal ini, diharapkan perusahaan dapat hidup secara berkelanjutan dan memberikan manfaat bagi para stakeholder. (dalam Riantono, 2014).

Ketua Dewan Komisioner OJK, Muliaman D. Hadad, menjelaskan bahwa beberapa waktu lalu ada penghargaan yang diberikan kepada 50 perusahaan di tingkat ASEAN yang dianggap menerapkan good corporate governance atau tata kelola perusahaan yang baik, tetapi hanya dua perusahaan asal Indonesia yang meraih penghargaan tersebut. Ini terlalu sedikit untuk negara sebesar Indonesia. Kita mengharapkan semakin banyak perusahaan yang masuk dan memenuhi kriteria good corporate governance ASEAN. Dengan demikian, perusahaan-perusahaan di Indonesia tidak hanya menjadi unggulan di negeri sendiri, tetapi juga di tingkat regional (Kompasonline, November 17, 2015). Sebelumnya penerapan Corporate Governance telah diteliti oleh lembaga bernama Asian Corporate Governance Association (ACGA) dengan subjek penelitian beberapa negara, yaitu: Singapore, Hongkong, Jepang, Taiwan, Thailand, Malaysia, India, Korea, China, Filipina, dan Indonesia. Berikut tabel peringkat dari hasil penelitian tersebut:

Daya Saing infrastruktur Indonesia masih tertinggal dibanding negara-negara kawasan Asia Tenggara seperti Singapura atau Malaysia. Namun, Indonesia lebih baik dari Vietnam maupun Filipina. Wilayah yang berbentuk kepulauan dengan luas 5,1 juta km persegi dan terbentang dari Sabang sampai Merauke menjadi tantangan bagi pemerintah untuk meningkatkan daya saing infrastruktur nasional.

Dalam laporan The Global Competitiveness Report 2018 skor pilar infrastruktur Indonesia berada di level 66,8 dari skala 0-100 dan berada di peringkat 71 dari 140 negara yang disurvei. Di tingkat ASEAN, Indonesia berada di posisi ke 5 di bawah Thailand dan di atas Vietnam. Skor daya saing infrastruktur Indonesia tersebut terpaut 28,88 poin dari Singapura yang merupakan negara dengan peringkat daya saing tertinggi di AsiaTenggara maupun di tingkat global. Pemerintahan telah berupaya memperbaiki daya saing Indonesia dengan meningkatkan anggaran pembangunan infrastruktur sejak 2015 menjadi Rp 256,1 triliun, naik 65\% dari tahun sebelumnya. Anggaran 


\section{Tyahya Whisnu Hendratni et al.}

Government investment in infrastructure,

infrastruktur terus meningkat menjadi Rp 410,4 triliun pada 2018. Untuk tahun ini, pemerintah menganggarkan dana Rp 415 triliun untuk pembangunan infrastruktur.

Tujuan Penelitian ini adalah untuk mengetahui bagaimana pengaruh Corporate Governance dan penerapan prinsip-prinsip Corporate Governance tersebut dalam kemitraan dan Badan Usaha (KPBU ) bidang Infrastruktur di Indonesia. Urgensi studi adalah dapat memberikan pengetahuan dan menggambarkan informasi secara umum terkait dengan pelaksanaan prinsip-prinsip Corporate Governance khususnya dalam bidang infrastruktur kepada publik.

\section{KAJIAN PUSTAKA}

\section{Good Corporate Governance}

Friendly (2017) dalam Penerapan Good Corporate Governance memberikan empat manfaat yaitu: meningkatkan kinerja perusahaan, mempermudah diperolehnya dana pembiayaan yang lebih mudah, mengembalikan kepercayaan investor untuk menanamkan modalnya di Indonesia, dan meningkatkan stakeholder's value. Good Corporate Governance terdiri dari dua unsur, yaitu: unsur yang berasal dari dalam perusahaan (Corporate Governance internal perusahaan) dan unsur yang berasal dari luar perusahaan (Corporate Governance eksternal perusahaan).

Penerapan dan pengelolaan corporate governance yang baik merupakan sebuah konsep yang menekankan pentingnya hak pemegang saham untuk memperoleh informasi dengan benar, akurat, dan tepat waktu. Selain itu juga menunjukkan kewajiban perusahaan untuk mengungkapkan semua informasi kinerja keuangan perusahaan secara akurat, tepat waktu dan transparan. Oleh karena itu, baik perusahaan publik maupun tertutup harus memandang good corporate governance bukan sebagai aksesoris belaka tetapi sebagai upaya peningkatan kinerja dan nilai perusahaan.

Penerapan dan pengelolaan Corporate Governance yang baik dan benar merupakan suatu konsep yang menekankan pada pemegang saham untuk memperoleh informasi yang benar, akurat, dan tepat waktu. Di era persaingan global sekarang ini yang namanya batas- batas negara tidak lagi menjadi hambatan untuk bersaing atau berkompetisi, hanya perusahaan- perusahaan yang menerapkan prinsip Good Corporate Governance (GCG) yang mampu memenangkan persaingan tersebut (Ignasius, 2014).

\section{Kemitraan Pemerintah dan Badan Usaha (KPBU)}

Menurut Peraturan Presiden Republik Indonesia Nomor 38 Tahun 2015 tentang kerjasama pemerintah dengan badan usaha dalam penyediaan infrastruktur pada pasal 1 ayat 6 yang isinya: "Kerjasama Pemerintah dan Badan Usaha yang selanjutnya disebut sebagai KPBU adalah kerjasama antara pemerintah dan Badan Usaha dalam Penyediaan Infrastruktur untuk kepentingan umum dengan mengacu pada spesifikasi yang telah ditetapkan sebelumnya oleh Menteri/Kepala Lembaga/ Kepala Daerah/ Badan Usaha Milik Negara/ Badan Usaha Milik Daerah, yang sebagian atau seluruhnya menggunakan sumber daya Badan Usaha dengan memperhatikan pembagian risiko diantara para pihak"

KPBU merupakan alat untuk meningkatkan efisiensi dan meningkatkan kualitas produkproduk dan pelayanan publik. Tujuan bersama yang hendak dicapai dengan menggunakan skema KPBU ini, antara lain, adalah untuk meningkatkan efektivitas dan efisiensi dalam pelaksanaannya, meningkatkan kualitas produk-produk dan pelayanan publik, dan adanya pembagian modal, risiko, dan kompetensi atau keahlian sumber daya manusia secara bersamaan. 


\section{METODOLOGI}

\section{Prosedur Sampel}

Menurut Uma sekaran (2011: 64) adalah keseluruhan kelompok orang, peristiwa, atau hal yang akan diteliti. Subyek Penelitian adalah orang yang dijadikan sumber data atau sumber informasi oleh peneliti untuk riset yang dilakukannya. Jadi Populasi dan subyek yang akan diteliti adalah sekelompok orang yang paham tentang Kemitraan Pemerintah dan Badan Usaha (KPBU) yaitu dari Perkumpulan Ahli Profesional Kemitraan Pemerintah dan Badan Usaha Indonesia (PAPKPBUI) yaitu sebanyak 142 orang.

\section{Pengukuran}

Jenis data yang digunakan pada penelitian ini menggunakan pendekatan kualitatif dengan Teknik purposive sampling. Teknik Purposive sampling adalah Teknik pengambilan sampel pada sumber data dengan pertimbangan tertentu, misalnya orang tersebut yang dianggap paling tahu tentang apa yang kita harapkan sehingga memudahkan penelitian yang akan diteliti (Sugiyono, 2011).

Jenis data yang digunakan adalah data primer. Data primer diperoleh dengan cara menyebarkan kuesioner dengan menggunakan gogle form ( karena pandemik efek ) kepada para pemangku kepentingan atau stakeholder antara lain terdiri dari : Government, Praktisi (Pengamat ) dan Akademisi. Untuk analisis data yang digunakan adalah menggunakan Teknik Estimasi regresi Ordinary Least Square ( OLS ). Pengolahan data dengan SPSS 23.

Untuk mengetahui pengaruh prinsip-prinsip CG dalam KPBU bidang Infrastruktur dengan regresi linear berganda terlebih dahulu dilakukan pengujian asumsi klasik, analisis statistik deskriptis dan uji goodness of fit agar tidak terjadi bias dalam melakukan pengujian. Data yang dianalisis adalah kelima prinsip CG. Nilai $r$ table dengan $n=142$ atau $\mathrm{df}=\mathrm{n}-2=140$ dan dengan signifikansi 0,05 maka didapat nilai $r$ table $=0,165$. Dapat diketahui semua item nilai korelasi tiap item skor totalnya lebih dari 0,165 jadi item kuesioner tersebut adalah valid. Menurut Sekaran ( 2003) dalam Priyatno ( 2013: 30) uji realibilitas antara 0,60 - 0,79 realibilitasnya diterima. Oleh karena itu Nilai Cronbach Alpha telah Menuhi standar reliabilitas karena nilainya adalah diatas 0,600 .

\section{HASIL DAN PEMBAHASAN}

Dibawah ini akan dibahas hasil analisis data statistik yaitu statistik Deskriptif dan analisis regresi. Pada Tabel 1 adalah menganalisis untuk mengetahui deskripsi data seperti mean , nilai minimum, nilai maksimum dan standar deviasi. Berikut ini disajikan statistik deskriptif tentang skor total variabel-variabel penelitian yaitu sebagai berikut :

Tabel 1.

Statistik Deskriptif

\begin{tabular}{|c|c|c|c|c|c|}
\hline & $\mathrm{N}$ & Minimum & Maximum & Mean & $\begin{array}{l}\text { Std. } \\
\text { Deviation }\end{array}$ \\
\hline Transparansi (X1) & 142 & 4 & 15 & 10.65 & 3.056 \\
\hline Akuntabilitas (X2) & 142 & 7 & 25 & 17.99 & 4.608 \\
\hline Responsibilitas (X3) & 142 & 5 & 20 & 14.1 & 3.671 \\
\hline Independensi (X4) & 142 & 3 & 15 & 11.37 & 2.936 \\
\hline
\end{tabular}


Tyahya Whisnu Hendratni et al.

Government investment in infrastructure,

\begin{tabular}{llllll}
\hline Keadilan (X5) & 142 & 5 & 20 & 13.92 & 3.781 \\
KPBU Bidang Infrastruktur (Y) & 142 & 7 & 25 & 17.67 & 4.586 \\
\hline Sumber: Data diolah 2020 & & &
\end{tabular}

Pada Tabel 1 terlihat bahwa dari 142 responden yang di teliti yang mempunyai nilai paling tinggi yaitu variabel Akuntabilitas ( X2) . Dimana mempunyai nilai maksimum sebesar $25 \%$, Nilai minimum 7\% dan nilai Means ( rata-rata ) 17.99\%. Dengan penyimpangan sebesar $4.608 \%$. Hal ini berarti bahwa menurut 142 responden yang terdiri dari Perkumpulan Profesional Kemitraan Pemerintah dan Badan Usaha Indonesia menganggap bahwa akuntabilitas lah yang merupakan faktor dominan yang mempengaruhi KPBU. Dengan akuntabilitas dapat mencegah penyalahgunaan wewenang dan menjamin tercapainya tujuan.

\section{Analisis Regresi}

Hasil uji Uji F menunjukkan bahwa model regresi sudah memenuhi goodness of fit. Hal ini dapat dilihat dari nilai $\mathrm{F}_{\text {hitung }}>\mathrm{F}_{\text {table }}(127.002>2$,281) maka Ho ditolak yang artinya Transparansi, Akuntabilitas , Responsibilitas, Indepedensi, dan Keadilan secara Bersama-sama berpengaruh terhadap KPBU Bidang Infrastruktur. Dapat diketahui bahwa variabel Transparansi , Akuntabilitas, Responsibilitas, Indepedensi secara bersama-sama memiliki sumbangan pengaruh terhadap KPBU bidang Infrastruktur sebesar 0,817 atau 81,7 \% dan sisanya dipengaruhi faktor lain yang tidak diteliti.

Tabel 2.

Regression Analysis

\begin{tabular}{lrllr}
\hline & B & Std.dev & \multicolumn{1}{r}{ t } & Sg. \\
\hline (Constant) & .562 & .714 & .787 & .433 \\
Transparansi $\left(\mathrm{X}_{1}\right)$ & .247 & .105 & 2.351 & .020 \\
Akuntabilitas $\left(\mathrm{X}_{2}\right)$ & .161 & .079 & 2.038 & .044 \\
Responsibilitas $\left(\mathrm{X}_{3}\right)$ & .291 & .095 & 3.056 & .003 \\
Independensi $\left(\mathrm{X}_{4}\right)$ & .210 & .098 & 2.142 & .034 \\
Keadilan $\left(\mathrm{X}_{5}\right)$ & .365 & .084 & 4.358 & .000 \\
& & & & \\
R & 0,908 & & & \\
Adj. R Square & 0,817 & & & \\
F-Statistics & & & & \\
& 127.002 & & &
\end{tabular}

\section{Transparancy Berpengaruh Positif Terhadap KPBU Bidang Infrastruktur}

Transparancy bermakna tersedianya informasi yang cukup, akurat dan tepat waktu. Karena dengan tersedianya informasi yang akurat dan tepat waktu maka masyarakat pada umumnya dan pihak berkepentingan lainnya dapat sekaligus mengawasi perusahaan sehingga kebijakan kebijakan yang dibuat oleh manajer dapat mencegah terjadinya kecurangan dan manipulasi yang hanya menguntungkan salah satu kelompok saja secara tidak proporsional. Begitupula apabila organisasi bisnis menerapkan prinsip transparancy maka akan meningkatkan tingkat kepercayaan stakeholder terhadap perusahaan, sehingga kinerja keuangan perusahaan akan menjadi lebih baik. 


\section{Akuntanbilitas Berpengaruh Positif Terhadap KPBU Bidang Infrastruktur}

Menurut Widodo (2011) dalam Martha (2014) accountability merupakan persyaratan mendasar untuk mencegah penyalahgunaan kewenangan yang didelegasikan dan menjamin kewenangan diarahkan pada pencapaian-pencapaian tujuan nasional yang diterima secara luas dengan tingkat efisiensi, efektifitas, dan kejujuran. Kejelasan wewenang dan fungsi pelaksanaan serta pertanggungjawaban struktur dalam perusahaan akan membuat pengelolaan perusahaan terlaksana secara efektif, dan pada akhirnya akan meningkatkan kinerja keuangan perusahaan.

\section{Responsibilitas Berpengaruh Positif Terhadap KPBU Bidang Infrastruktur}

Karena untuk dapat meningkatkan kinerjanya, perusahaan harus mampu memahami dan mematuhi peraturan serta melaksanakan tanggung jawab terhadap stakeholders sehingga perusahaan dapat tumbuh secara berkesinambungan. Dengan mematuhi peraturan dan melaksanakan tanggung jawabnya tersebut, maka kinerja keuangan perusahaan akan meningkat.

\section{Indepedency Berpengaruh Positif Terhadap KPBU Bidang Infrastruktur}

Indepedency adalah suatu keadaan dimana perusahaan dikelola secara profesional tanpa benturan kepentingan dan pengaruh atau tekanan dari pihak manapun yang tidak sesuai dengan peraturan perundang-undangan yang berlaku dan prinsip-prinsip korporasi yang sehat (Suci, 2013). Kebebasan mengelola perusahaan tanpa benturan kepentingan dari pihak lain penting untuk diperhatikan dalam usaha untuk meningkatkan kinerja dan memastikan bahwa perusahaan telah bersikap secara objektif.

\section{Keadilan / Fairness Berpengaruh Positif Terhadap KPBU Bidang Infrastruktur}

Fairness merupakan keadilan dan kesetaraan di dalam memenuhi hak-hak stakeholders yang timbul berdasarkanperjanjian dan peraturan perundang- undangan yang berlaku. Dengan demikian hasil penelitian ini menunjukkan bahwa kewajaran berpengaruh terhadap kinerja keuangan. Organisasi bisnis seyogyanya dapat memperhatikan hak dari pemangku kepentingan berdasarkan asas kewajaran dan kesetaraan dalam rangka meningkatkan kinerja keuangan perusahaan agar terlaksana efektif.

\section{Penerapan KPBU di Indonesia yang terkait dengan Keadilan / Fairness}

Kerjasama Pemerintah dengan badan Usaha ( KPBU) akan berjalan lancar apabila seluruh stakeholders yang terlibat mampu berkoordinasi dengan baik. Koordinasi dilakukan dengan cara mengadakan rapat rutin setiap bulan. Rapat dinas setiap 3 bulan sekali serta rapat koordinasi setiap 3 bulan sekali yaitu rapat koordinasi Tim Pengembang terkait penyediaan infrastruktur. Pemerintah dalam hal ini berusaha untuk dapat menyediakan berbagai fasilitas yang dapat menunjang pengembangan infrastruktur. Badan usaha Pelaksana mencari peluang dalam usaha melaksanakan penyediaan infrastruktur.

Stakeholders mempunyai peranan yang sangat penting dalam pengembangan infrastruktur. Pemerintah membutuhkan bantuan dan dukungan dari aktor lainnya baik dari segi finansial maupun tenaga agar kerjasama Pemerintah dengan Badan Usaha dapat berjalan dengan lancar. Stakeholders memiliki peranan tersendiri sesuai dengan tugas dan fungsinya. 


\section{Tyahya Whisnu Hendratni et al.}

Government investment in infrastructure,

a Kerjasama Pemerintah dengan Badan Usaha akan berjalan lancar apabila seluruh stakeholders yang terlibat mampu berkoordinasi dengan baik.

b Tanggung jawab tetap melekat pada Pemerintah. Pemerintah berkewajiban untuk memenuhi tanggung jawab sosial ekonomi kepada masyarakat. Tuntutan masyarakat untuk memperoleh pelayanan yang lebih baik harus disikapi sebagai upaya untuk menciptakan kepuasan dalam pemberian pelayanan kepada masyarakat secara adil, merata , cepat dan tepat.

c Keterlibatan badan usaha dalam menangani urusan publik yang diberikan pemerintah sekaligus menumbuhkan tumbuhnya partisipasi masyarakat dalam pembangunan karena dirasakan bahwa badan usaha lebih cepat dan efisien bila dibandingkan dengan yang ditangani oleh Pemerintah. Efisiensi cara kerja ,kualitas SDM yang mereka miliki , kecepatan adopsi terhadap perkembangan teknologi sering menjadi alasan menagapa Pemerintah perlu melibatkan Badan Usaha.

\section{KESIMPULAN}

Penelitian ini memperlihatkan bahwa stakeholders mempunyai peranan yang sangat penting dalam pengembangan infrastruktur. Kerjasama Pemerintah dengan Badan Usaha akan berjalan lancar apabila seluruh stakeholders yang terlibat mampu berkoordinasi dengan baik. Tanggung Jawab tetap melekat pada Pemerintah. Dimana Pemerintah berkewajiban untuk memenuhi tanggung jawab sosial ekonomi kepada masyarakat. Tuntutan masyarakat untuk memperoleh pelayanan yang lebih baik harus diupayakan sehingga dapat memuaskan masyarakat secara adil, merata, cepat dan tepat. Agar KPBU ini dapat berhasil, maka diperlukan kerjasama yang bersifat saling melengkapi , saling memberikan informasi, saling terintegrasi dan setiap institusi dapat menunjukkan identitas dan posisi yang jelas.

\section{Implikasi}

Tanggung jawab terbesar di tangan pemerintah . Badan Usaha yang menangani urusan pemerintah tetap berada dibawah kontrol pemerintah. Pemerintah mengontrol berdasarkan atas apa yang telah ditetapkan sedangkan masyarakat mengontrol melalui apa yang dirasakannya atas kinerja dari badan usaha yang menangani urusan publik. Pihak badan usaha dengan demikian tidak semena-mena melaksanakan dan menggunakan apa yang dikehendakinya tetapi sesuai dengan aturan terutama kehendak dari masyarakat.

Pemerintah sebaiknya melakukan kajian yang cermat dan matang terlebih dahulu kegiatan atau proyek mana yang dapat dan layak dilakukan. Pemerintah harus menetapkan aturan-aturan yang tidak memberikan keuntungan yang terlalu besar kepada badan usaha dengan tidak merugikan masyarakat. Harus dicermati dengan teliti pasal-pasal dalam peraturan kerjasama bila hanya akan menguntungkan pihak swasta dan merugikan masyarakat. Agar pemerintah mendapat respon yang positif sementara rakyat juga memperoleh hasil yang sepadan yaitu tercapainya kesejahteraan oleh karenanya Pemerintah diharapkan untuk dapat meningkatkan layanan publik.

\section{Keterbatasan dan Saran}

Penelitian ini hanya terbatas pada jumlah responden sebanyak 142 responden dan terbatas pada sekelompok orang yang paham tentang Kemitraan Pemerintah dan Badan Usaha (KPBU) yaitu dari Perkumpulan Ahli Profesional Kemitraan Pemerintah dan Badan Usaha Indonesia (PAPKPBUI), sehingga kurang akuratnya hasil penelitian jika ditujukan pada populasi yang lebih luas. 
Jurnal Manajemen Strategi dan Aplikasi Bisnis, Volume 4, Nomor. 1, 2021. 198- 206

Selain itu, penelitian ini hanya terbatas pada penggunaan lima variabel independen yaitu Transparansi, Akuntabilitas, Responsibilitas,Indepedensi dan Keadilan / fairness. Dengan demikian, penelitian di masa depan dapat menggunakan sampel responden yang lebih besar dan memperluas variabel penelitian seperti kinerja keuangan ataupun manajemen resiko sehingga hasil penelitian akan lebih valid dan populasi lebih luas.

\section{REFERENCES}

Chinn. (2000). Corporate Governance Handbook. Gee Publishing Ltd.

Friendly, E. (2017). Analisis penerapan Prinsip - Prinsip GCG Pada Perusahaan Milikkeluarga Bidang Perhotelan. Jurnal Agora, 5(3).

Ignatius, E. R. (2014). Pengelolaan Manajemen dalam mewujudkan good corporate governance;optimalisasi pencapaian tujuan perusahaan. Binus Business Review, 1(5), 315322.

Martha, W. (2016). Pengaruh Transparansi Dan Akuntabilitas Terhadap Kinerja Instansi Pemerintah Pada Dinas Di Kota Bandung (Survey diInstansi Pemerintah Kota Bandung). Universitas Widyatama.

Shaw, J. (2003). Corporate Governance And Risk : A System Approach. John Wiley \& Sons, Inc.

Suci, Y. (2013). Pengaruh Penerapan Prinsip Good Corporate Governance Terhadap Kinerja Perusahaan Pada PT. Kereta Api (Persero) Divisi Regional III Sumatera Selatan.

Sugiyono. (2011). Metode penelitian kuantitatif, kualitatif, dan R\&D. Alfabeta.

\section{Competing interests}

The authors declare that they have no competing interests.

\section{Funding.}

The authors received no financial support for the research and publication of this article.

\section{About the Authors}

Dr. Tyahya Whisnu Hendratni , S.E., M.M. is a lecturer at the Faculty of Economic and Business at the University of Pancasila, Jakarta . S1, S2 , S3 she is concentrating in the field of Financial Management. She is actively writing in several Journals. She is also a reviewer in several accredited journals.

Hindradjid Harsono, S.E., M.Si. is a lecturer at the Faculty of Economic and Busineses at the University of Pancasila, Jakarta , in the field of Accouting.

Drs. Soemarsono DW, M.M., Ak. CA is a lecturer at the Faculty of Economic and Busineses at the University of Pancasila, Jakarta , in the field of Accouting. 